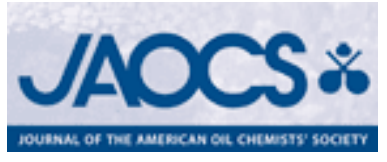

\title{
Effect of Feed Fat By-products with Trans Fatty Acids and Heated Oil on Cholesterol and Oxycholesterols in Chicken
}

\begin{tabular}{|c|c|}
\hline Journal: & Journal of the American Oil Chemists Society \\
\hline Manuscript ID: & JAOCS-09-0167.R2 \\
\hline Manuscript Type: & Original Article \\
\hline \multicolumn{2}{|l|}{$\begin{array}{r}\text { Date Submitted by the } \\
\text { Author: }\end{array}$} \\
\hline Complete List of Authors: & $\begin{array}{l}\text { Ubhayasekera, Sarojini; Swedish University of Agricultural } \\
\text { Sciences, Division of Food Chemistry, Department of Food Science, } \\
\text { Tres, Alba; University of Barcelona, Nutrition and Food Science } \\
\text { Department-XaRTA } \\
\text { Codony, Rafael; University of Barcelona, Nutrition and Food Science } \\
\text { Department-XaRTA } \\
\text { Dutta, Paresh; Swedish University of Agricultural Sciences,, Division } \\
\text { of Food Chemistry, Department of Food Science, }\end{array}$ \\
\hline Keywords: & $\begin{array}{l}\text { Food and Feed Science / Nutrition and Health, Fats and oils, Co- } \\
\text { products (Waste) \&amp;amp;amp;amp;amp;lt; Biobased Products, } \\
\text { Oxidative Stability \&amp;amp;amp;amp;It; Food and Feed Science } \\
\text { / Nutrition and Health, Lipid Chemistry / Lipid Analysis, } \\
\text { Autoxidation \&amp;amp;It; Lipid Chemistry / Lipid Analysis }\end{array}$ \\
\hline
\end{tabular}

\section{S ScholarONE


Revised title: Effect of Feed Fat By-products with Trans Fatty Acids and Heated

\section{Oil on Cholesterol and Oxycholesterols in Chicken}

Sarojini J. K. A. Ubhayasekera ${ }^{a^{*}}$, Alba Tres ${ }^{b}$, Rafael Codony ${ }^{b}$, Paresh C. Dutta ${ }^{a}$

${ }^{a}$ Division of Food Chemistry, Department of Food Science, Swedish University of Agricultural Sciences, Box 7051, SE-75007, Uppsala, Sweden

${ }^{b}$ Nutrition and Food Science Department-XaRTA - INSA, Faculty of Pharmacy, University of Barcelona, Spain

${ }^{*}$ Correspondence to:

Sarojini J. K. A. Ubhayasekera,

Department of Food Science, Division of Food Chemistry,

Swedish University of Agricultural Sciences, SLU

Box 7051, SE-750 07, Uppsala, Sweden.

E-mail: Kumari.Ubhayasekera@1mv.slu.se

Tel: +4618672051

Fax: +4618672995 


\begin{abstract}
Chicken is the most widely consumed meat all over the world due to easy to rear, fast growth rate and good nutritional characteristics. The main objective of this paper was to study the effects of dietary fatty by-products in low, medium and high levels of oxidized lipids and trans fatty acids on the contents of cholesterol and oxycholesterols in meat, liver, and plasma of chickens. A palm fatty acid distillate, before and after hydrogenation, and a sunflower-olive oil blend $(70 / 30 \mathrm{v} / \mathrm{v})$ before and after use in a commercial frying process were used in feeding trials after adding $6 \%$ of the fats to the feeds. Highly oxidized lipid and trans fatty acid feeds significantly increased the contents of cholesterol and oxycholesterols in all tissues of chicken $(0.01<p \leq 0.05)$. The contents of oxycholesterols in chicken meat, liver and plasma obtained from trans fatty acid feeding trials varied between $17-48 \mu \mathrm{g} / 100 \mathrm{~g}$ in meat, $19-42 \mu \mathrm{g} / 100 \mathrm{~g}$ in liver and $105-126 \mu \mathrm{g} / \mathrm{dL}$ in plasma. In contrast, in the oxidized lipid feeding trials, oxycholesterols varied between $13-75 \mu \mathrm{g} / 100 \mathrm{~g}$ in meat, $30-58 \mu \mathrm{g} / 100 \mathrm{~g}$ in liver and 66$209 \mu \mathrm{g} / \mathrm{dL}$ in plasma. Chicken fed with feeds containing high levels of trans fatty acids or oxidized lipids may contribute to higher ingestion by human of cholesterol and oxycholesterols.
\end{abstract}

Key words: Chicken tissues, cholesterol, COPs, feed fat, oxidized lipids, trans fatty acids 


\section{Introduction}

Thermally oxidized lipid is commonly considered to contain potentially toxic lipid oxidation products, which are readily absorbed by animals and may induce oxidative stress [1]. Studies in rabbit, chicken, and other susceptible species showed that dietary cholesterol and oxycholesterols can lead to atherosclerosis [1-3]. Cholesterol and cholesterol oxidation products (COPs, oxycholesterols) are also known to be a risk factor for coronary heart disease (CHD) and COPs may have cytotoxic, mutagenic and atherogenic effects, and thus harmful to humans [4].

Little is known about the effects of dietary TFA in formulated feed on animal fat deposition, and their subsequent effects on human health in quantitative terms. In some animals, dietary trans fatty acids (TFA) increase total cholesterol and LDL-cholesterol and tend to decrease HDL-cholesterol, possibly due to increased cholesteryl ester transfer protein (CETP) activity in plasma [5, 6]. Recently, it was shown that female broilers fed a TFA-containing diet had similar body fat and protein contents and did not differ significantly from the control group except for body fatty acid composition. The authors showed that $50 \%$ of ingested TFA was incorporated into the body fat and that it could negatively affect the nutritional value of chicken meat [7]. As far as we know, there are no previous reports on the content of COPs in chicken tissues fed with different levels of TFA.

Chickens, like other animals, biosynthesize cholesterol or ingest it from the diet, and its level in body tissue can be modulated by feed lipids [8,9]. This in vivo cholesterol may undergo enzymatic oxidation, mainly during biosynthesis of bile acids and steroid 
hormones. Moreover, cholesterol can be oxidized to COPs in vivo by hydroxy radicals $\left(\mathrm{OH}^{\circ}\right)$, alkoxy radicals $\left(\mathrm{RO}^{\circ}\right)$ and peroxy radicals $\left(\mathrm{ROO}^{\circ}\right)$ formed during lipid peroxydation and COPs may also originate from the diet [10]. Grau et al. (2001) have observed that the dietary lipid sources including beef tallow, fresh and oxidized sunflower oils had no considerable effect on the content of cholesterol in raw chicken meat, whereas the content of COPs was significantly higher only in the chicken fed with sunflower oil [11]. In contrast, Bonoli et al. (2007) have reported that chickens fed with animal fat had significantly higher contents of cholesterol and COPs in meat compared with chicken fed with vegetable oil based feeds [12].

To prepare animal feeds, fats and oils from various sources can be added, including used frying oil, by-products from edible fats and oil refining, or fatty acid distillates [13]. However, to our knowledge their effects on the meat product quality, specifically in terms of cholesterol and COPs in chicken have not been investigated earlier. In the present study, we investigated the effect of heated (oxidized) oils (OXL) and trans fatty acids in feeding fats obtained from by-products of the food chain on the levels of cholesterol and COPs in chicken meat, liver, and plasma.

\section{Materials and Methods}

\section{Experimental Oils}

In the TFA and the OXL trials, two types of fat by-products were used. These fats contained 'high' and 'low' levels of TFA and OXL, respectively, which were assessed in the trials. The selected fats were commercially available and similar in other characteristics to minimize the errors. The 'low' TFA fat $(0.14 \%$ total TFA, $\alpha$-tocopherol 


\section{Animal Feeds and Experimental Protocol}

Experimental feeds for chicken were formulated according to their nutritional requirements [14]. The feed ingredients and nutrient composition in the chicken feed are given in Table 1. To reduce dietary variations other than the added fat, the following was done: i) the same batches of each one of the seven raw materials tested were used in all experimental feeds, ii) batches of basal mix were prepared and then subdivided to obtain identical participation of each batch in each experimental feed. Samples of all raw materials were checked for confirmation of low dioxin/polychlorinated biphenyls (PCBs), polycyclic aromatic hydrocarbons (PAHs) and polybrominated diphenyl ethers (PBDEs) content.

The protocols followed in chicken trials were approved by the Animal Protocol Review Committee of the University Autonoma of Barcelona. The protocols, housing, husbandry and slaughtering conditions conformed to current European Union guidelines. For each 
trial (TFA and OXL), 96 female chickens (Ross 308, 7 days old) were randomly distributed into three different dietary treatments (high, medium, and low) with 8 replicates per treatment and 4 chickens constituting each replicate. Standard temperature, humidity and ventilation conditions were provided. In all cases, feed and water were given ad libitum. At 40 experimental days, chickens were sacrificed in a commercial slaughterhouse.

\section{Preparation of Meat, Liver and Plasma Samples}

Chicken meat samples corresponded to de-boned dark leg meat with skin and each replicate were ground in a mixer until a suitable homogeneous sample was obtained. Representative sub-samples for each analysis (15-20 g) were vacuum packed, and stored at $-20^{\circ} \mathrm{C}$ until further analysis. Each replicate contained livers from four chickens and mixture of livers ground until it get homogenized, then vacuum packed in plastic bags and stored at $-20^{\circ} \mathrm{C}$ until further analysis. Chicken plasma samples were collected from 4 animals from each replicate by means of a syringe, placed in heparinized tubes, and centrifuged at $4^{\circ} \mathrm{C}$ and $1400 \mathrm{~g}$ for 10 minutes. The plasma was separated, mixed well, and divided into aliquots that were transferred to plastic tubes ( $4.5 \mathrm{~mL}$ capacity) and stored at $-20^{\circ} \mathrm{C}$

\section{Determination of Cholesterol in Meat, Liver and Plasma}

The content cholesterol was determined by the direct saponification method as described previously with slight modification [15]. In brief, about $100 \mathrm{mg}$ of chicken meat or liver and $5 \alpha$-cholestane $(10-20 \mu \mathrm{g})$ were saponified with $4 \mathrm{~mL} 2 \mathrm{M} \mathrm{KOH}$ in $95 \%$ ethanol in a glass tube at $100^{\circ} \mathrm{C}$ for 15 minutes in a water bath. For chicken plasma, the same method was used except that each $100 \mu \mathrm{L}$ sample was saponified with $1 \mathrm{~mL}$ of $2 \mathrm{M} \mathrm{KOH}$. The 
extraction of sterol, preparation of trimethylester derivatives of cholesterols, and quantification by GC were done as described earlier [16].

\section{Determination of Oxycholesterols (COPs) in Meat and Liver}

\section{Extraction of Lipids}

A slightly modified method of lipid extraction was used [17]. In brief, approximately $10 \mathrm{~g}$ meat samples or $8 \mathrm{~g}$ liver samples were homogenized with $25 \mathrm{~mL}$ of HIP (hexane/isopropanol; 3:2, v/v) using an Ultra-Turrax $\mathrm{T}_{25}$ homogenizer (S 25N-8G) (Jankel \& Kunkel GmbH, Staufen, Germany). Next $10 \mathrm{~mL}$ of an aqueous $6.67 \%$ $\mathrm{Na}_{2} \mathrm{SO}_{4}$ was added and mixed thoroughly. The upper organic solvent phase was collected after centrifuged samples and the remaining sample was re-extracted three times with $12.5 \mathrm{~mL}$ hexane. The solvent was evaporated using a rotary evaporator under vacuum at $30^{\circ} \mathrm{C}$ and dry lipids were stored at $-20^{\circ} \mathrm{C}$ until further analysis.

\section{Cold Saponification and Enrichment of COPs}

The COPs were enriched by cold saponification of the extracted lipids (approximately $300 \mathrm{mg}$ ) from both meat and liver and then further enriched by solid phase extraction (SPE) to remove unoxidized cholesterol and derivatized to trimethylsilyl (TMS) ether prior to analysis by GC and GC-MS as described previously [18].

\section{Determination of COPs by $G C$}

Analysis of COPs was performed using an Agilent GC 6890N and ChemStation Rev. B.02.01 software (Agilent Technologies, Wilmington, DE, USA) equipped with an auto-sampler (CTC Analytics AG, Zwingen, Switzerland). Two fused silica capillary columns DB5-MS (15 m x $0.18 \mathrm{~mm}, 0.18 \mathrm{~mm})$ and DB35-MS (10 m x $0.2 \mathrm{~mm}$, 
$0.18 \mathrm{~mm}$ ) (J \& W Scientific, Folsom, CA, USA) connected by a universal pressfit connector in the order of decreasing polarity were used for separation and quantification of COPs. The initial oven temperature was $60^{\circ} \mathrm{C}$ for 1 minute, then increased to $290^{\circ} \mathrm{C}$ at a rate of $50^{\circ} \mathrm{C} / \mathrm{min}$ and maintained for 10 minutes, then raised to $300^{\circ} \mathrm{C}$ at a rate of $0.8^{\circ} \mathrm{C} / \mathrm{min}$ and maintained for another 7 minutes. The detector and injector were set at $320^{\circ} \mathrm{C}$ and $260^{\circ} \mathrm{C}$, respectively. The TMS ether derivatives of the COPs were injected at splitless mode of injection. Helium was used as carrier gas and nitrogen as make-up gas at a flow rate of 0.7 and $30 \mathrm{~mL} / \mathrm{min}$, respectively. Quantification of COPs was accomplished using $5 \alpha$-cholestane as the internal standard. The retention times were compared against standard COPs for peak identification.

\section{Identification of COPs by GC-MS}

Further structural confirmation of COPs was done by Voyager mass spectrometer with Xcalibur version 1.2 software (Finnigan, TheromQuest, Manchester, UK) coupled to a 8000 Top Series gas chromatograph and a AS800 autosampler (CE Instruments, ThermoQuest Italia S.p.A., MI, Italy) coupled to a The COPs were separated on a similar column, except that the length of the DB5MS column was $20 \mathrm{~m}$, as used in GC analysis. Helium was used as carrier gas at an inlet pressure of $80 \mathrm{kPa}$. The injector temperature was $250^{\circ} \mathrm{C}$ and the samples were injected in a splitless mode of injection. Oven temperature was $60^{\circ} \mathrm{C}$ for 1 minute, then raised to $290^{\circ} \mathrm{C}$ at a rate of $50^{\circ} \mathrm{C} / \mathrm{min}$ for 10 minutes, and finally the temperature was raised to $300^{\circ} \mathrm{C}$ at a rate of $0.8^{\circ} \mathrm{C} / \mathrm{min}$ for another 7 minutes. The mass spectra were recorded at electron energy of $70 \mathrm{eV}$ and the ion source temperature was $200^{\circ} \mathrm{C}$. The spectra were scanned in the range 50-600 $\mathrm{m} / \mathrm{z}$. Identification of the COPs was done by comparing mass spectra of standard 
samples of COPs. A list of the COPs analyzed in this study along with retention times (RT), relative retention times (RRT) in relation to $5 \alpha$-cholestane, a GC-MS chromatogram and the full scan mass spectra of the standard COPs, are shown in Table 2 and Figures 1-2, respectively.

\section{Determination of COPs in Plasma}

\section{Cold Saponification and Enrichment of COPs}

COPs were enriched by saponification of $1 \mathrm{~mL}$ of plasma with $5 \mathrm{~mL}$ of $10 \% \mathrm{KOH}$ in 95\% EtOH at room temperature for 18 hours in the dark, following a method described previously with some modifications [19]. The reaction was stopped by addition of 5 $\mathrm{mL}$ of saturated $\mathrm{NaCl}$ solution. The unsaponifiables were then extracted twice with 2 $\mathrm{mL}$ of hexane. The pooled hexane phase was washed with $5 \mathrm{~mL}$ of $5 \% \mathrm{NaOH}$ solution and then the upper phase was washed with $5 \mathrm{~mL}$ saturated $\mathrm{NaCl}$ solution. The hexane phase was dried under nitrogen and dissolved in $500 \mu \mathrm{L}$ of hexane: diethyl ether (75:25). The fraction containing COPs was enriched by SPE, except that $6 \mathrm{~mL}$ of hexane: diethyl ether $(60: 40, \mathrm{v} / \mathrm{v})$ was used for second wash of the SPE cartridge and quantified by GC as described above.

\section{Statistical Analysis}

Unless stated otherwise, all results are expressed as the mean of four replicates. Pearson's correlation and one-way ANOVA (analysis of variance) with TFA and oxidized lipid treatments at three levels were performed using the GLM option in Minitab. $p$-values $\leq 0.05$ were considered statistically significant. 


\section{Results and Discussion}

The meat, liver and plasma samples of chickens from low, medium, and high levels of both the TFA (basal + trans fatty acid) and OXL (basal + oxidized lipid) experiments were assessed for total cholesterol and cholesterol oxidation products (COPs).

Determination of total cholesterol was conducted by direct saponification of the meat, liver and plasma samples. The COPs were analyzed on the extracted lipids from meat and liver and direct saponification of the plasma samples at room temperature. The most common COPs were identified. i.e., $\beta$-ring oxidation products such as $7 \alpha-$

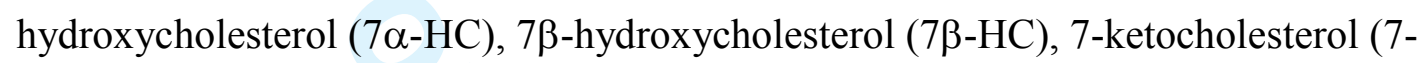
$\mathrm{KC}$ ), cholesteroltriol (CT), and epoxy isomers ( $\alpha$-epoxycholesterol $(\alpha-\mathrm{CE}), \beta$ epoxycholesterol ( $\beta-\mathrm{CE}))$, and common side-chain COPs such as $20 \alpha-$ hydroxycholesterol (20 $\alpha-\mathrm{HC})$ and 25-hydroxycholesterol (25-HC); however, none of the samples contained quantifiable amounts of $20 \alpha-\mathrm{HC}(<0.1 \mu \mathrm{g} / 100 \mathrm{~g}$ sample $)$. The purity of the identified peaks of the COPs in the tissue samples were checked by comparing their MS-data with standard COPs as shown in Figures 1-2. The values reported are means of analyses of 4 replicates from each treatment $(n=4)$.

The inclusion of high TFA fat in feed increased cholesterol level in chicken meat from 94 to $107 \mathrm{mg} / 100 \mathrm{~g}$ (Figure 3a), and had a strong positive co-relation and significant effect $(0.912 ; 0.01<p \leq 0.05)$. Among the COPs, 7-HC isomers and 7-KC were prominent, which increased 2-fold and 7-fold, respectively, from low to high levels of TFA fed chicken. Total content of COPs increased from 17 to $48 \mu \mathrm{g} / 100 \mathrm{~g}$ from low to high TFA diet, and had a strong positive co-relation and significant effect ( 0.905 ; $0.01<p \leq 0.05$ ) in chicken meat (Table 3). The content of cholesterol in chicken meat increased from 84 to $104 \mathrm{mg} / 100 \mathrm{~g}$ (Figure 3a) from low to high level of OXL, and 
had a strong positive co-relation and significant effect $(0.997 ; 0.01<p \leq 0.05)$. The total amount of COPs increased from 13 to $75 \mu \mathrm{g} / 100 \mathrm{~g}$ in chicken meat from low to high levels of OXL in feed, and had a strong positive co-relation and significant effect $(0.867 ; 0.01<p \leq 0.05)$. Among the quantified COPs, 7-HC isomers and 7-KC were the most frequent major ones (Table 3). In addition, considerable amounts of CT and 25HC were observed only in the meat of chicken fed with high levels of OXL. The cholesterol levels in chicken meat values presented in this paper are generally within the ranges of the published data [20-22] In a study with dietary beef tallow, fresh and oxidized sunflower oil and linseed oil, no significant differences were observed in the cholesterol level (96 - $99 \mathrm{mg} / 100 \mathrm{~g})$ in raw chicken meat [11]. On the other hand, Bonoli et al. (2007) observed that fresh meat from chickens fed with animal fat had significantly higher cholesterol level than that from chickens fed with vegetable oil in the feed. The levels of cholesterol were however quite low, 56 and 36 $\mathrm{mg} / 100 \mathrm{~g}$, in the meat of chicken fed with animal fat and vegetable oil, respectively. The level of cholesterol obtained was much lower than our results, possibly because meat samples were analyzed without skin in that study [12].

The content of COPs found in chicken meat was increased as a result of high TFA and OXL feeds. One of the reasons was these of these increased COPs may be resulted from TFA and OXL feeds. Among the COPs, 7-KC, CT, and 25-HC were present in considerable high amounts, and all these COPs have been detected in animal tissues [23]. It has been suggested that 7-KC is formed both in vivo and in vitro through dehydration of the epimers of 7-HC, and CT is the hydration product of cholesterol epoxides [22]. Mechanism of the generation of the side-chain oxidation product of cholesterol (25-HC) in vivo is not yet clearly understood [24]. Whether the high 
amount of 25-HC in the present study in high OXL feed was the result of the high

level of oxidized lipids in the diet, which facilitated oxidation of cholesterol at the

tertiary carbon atom at position 25 , remains to be explored. To our knowledge, no

study has been conducted previously on the effects of feed containing TFA on in vivo

formation of COPs in chicken. The TFA are unsaturated fatty acids that contain at least

one double bond and high level of TFA is considered to be associated with oxidative

stress in vivo [23], and may be associated with the formation of COPs [25]. Other

factors may affect cholesterol oxidation in meat from animals fed high TFA or high

OXL feeds. The contents of tocopherols in feeds decreased to some extent from low to

high TFA (16 to $14 \mathrm{mg} \alpha$-tocopherol/kg feed), because of hydrogenation, and

decreased also from low to high OXL (52 to $41 \mathrm{mg} \alpha$-tocopherol/kg feed)

(unpublished). In spite of higher amounts of $\alpha$-tocopherol in the OXL feeds but

resulted consistently in higher contents of COPs in the tissues of chicken compared

with the TFA feeds. This may be due to the destruction of $\alpha$-tocopherol in the

gastrointestinal tract by free radicals present in OXL feed or in the tissues by other

oxidation products, which were absorbed from heated oils in the OXL feed [26].

However within TFA and OXL feeds, the differences in the $\alpha$-tocopherol levels were

minimal. If such low differences in tocopherol contents affect in vivo cholesterol

oxidation need to be studied.

It has been observed that fresh chicken meat contains very low amounts of COPs compared with processed chicken meat. And dietary supplementation of $\alpha$-tocopherol can reduce the formation of COPs during processing [10, 21, 22, 27]. Tissue components in animals such as fat (mainly triacylglycerols), phospholipids, cholesterol and other polar compounds are susceptible to oxidation by molecular oxygen [10]. 
High OXL diet in this study was enriched with high amounts of peroxyl and alkoxyl radicals, which may also facilitate COPs formation in vivo. A few previous reports have shown contradictory results on in vivo formation of COPs in chicken e.g. it was shown that meat samples from oxidized and unoxidized sunflower oils and beef tallow fed chicken contained $1.42,1.90$ and $1.26 \mu \mathrm{g} / \mathrm{g}$ total COPs, respectively [11]. However, in another study animal fats and vegetable oil feeds generated 1.1 and 0.7 $\mu \mathrm{g} / \mathrm{g}$ total COPs, respectively, in chicken raw meat [12]. These differences in the results may be due to the presence of other compounds in the feeds such as fatty acid composition, natural oxidants, and pro-oxidant in the diet. These compounds may alter the levels of cholesterol and COPs in the body.

The high TFA fat in feed increased the amount of cholesterol from 350 to $428 \mathrm{mg} / 100$ $\mathrm{g}$ in chicken liver (Figure 3b) with respect to a low TFA feed, and showed a strong positive co-relation and significant effect $(0.919 ; 0.01<p \leq 0.05)$. Among the COPs, 7 $\mathrm{HC}$ isomers, $\mathrm{CE}$ isomers, and 7-KC were prominent in chicken liver at all TFA feed levels. Total content of COPs increased from 19 to $42 \mu \mathrm{g} / 100 \mathrm{~g}$ from low to high TFA feed, and had a strong positive co-relation and significant effects $(0.905 ; 0.01<p$ $\leq 0.05$ ), with the content of total COPs in chicken liver (Table 4).

The content of total cholesterol increased from 314-394 mg/100 g in liver from the low to high level of OXL fed chicken (Figure 3b) and had a strong positive co-relation and significant effect $(0.822 ; 0.01<p \leq 0.05)$. The content of total COPs increased from 30 $58 \mu \mathrm{g} / 100 \mathrm{~g}$ from low to high OXL in feed (Table 4). 7-HC isomers and 7-KC were the most commonly quantified COPs, where $7 \alpha-\mathrm{HC}, 7 \beta-\mathrm{HC}$, and 7-KC increased 3fold, 2-fold, and 2.5-fold from the low to the high level of OXL in feed, respectively. 
Levels of OXL in feeds had strong positive correlation and significant effects $(0.823$; $0.01<p \leq 0.05)$ on total COPs in chicken liver.'

In the present study, liver cholesterol levels in chicken can be affected by both TFA and OXL feeds. High TFA and OXL levels in the diet caused higher cholesterol and COPs levels in chicken liver compared with low and medium diets. The COPs in liver can be formed both from enzymic and non-enzymatic pathways. The non-enzymatic production COPs might be facilitated by high-energy free radicals from the high OXL diet. It has been suggested that the formation of COPs in vivo is affected by oxidized lipids in the diet [24].

The content of total cholesterol in plasma increased from 61 to $87 \mathrm{mg} / \mathrm{dL}(0.01<p$ $\leq 0.05)$ and from 100 to $126 \mathrm{mg} / \mathrm{dL}(0.01<p \leq 0.05)$ in chicken, from low to high feed levels of TFA and OXL, respectively (Figure 3c). The results also showed strong positive co-relations ( 0.998 and 0.992 , respectively). All the common COPs were observed in various quantities at all levels of TFA and OXL in feed. The content of total COPs increased from 105 to $126 \mu \mathrm{g} / \mathrm{dL}$ in plasma of chicken from low to high levels of TFA feed and this increase was much more prominent (66 to $209 \mu \mathrm{g} / \mathrm{dL}$ ) in OXL feed. These results had strong positive co-relations and significant effects, $(0.906 ; 0.01<p \leq 0.05)$ and $(0.958 ; 0.01<p \leq 0.05)$, respectively (Table 5). Among the COPs, $\beta-\mathrm{CE}$ was prominent and was present in high amounts, whereas $\alpha-\mathrm{CE}$ increased moderately in chicken plasma from the low to high level of TFA and about three times more in OXL trials. In plasma, 7 $\beta$-HC and 7-KC increased 2-fold and 5-fold, respectively, and the contents of $7 \alpha-\mathrm{HC}$ and CT were virtually unchanged in chicken from the TFA feeding experiments. 
All major COPs were observed comparatively in high quantities at high OXL feed compared with TFA feed except for $\beta$-CE. The highest individual oxycholesterol increasing rate were observed for $7 \mathrm{KC}$ and $25-\mathrm{HC}$ ca. 6 times for each, compared with low OXL feeds in chicken plasma (Table 5). In addition, $7 \alpha-\mathrm{HC}$ and $\mathrm{CT}$ and also increased in high amounts from low to high OXL in feed.

Contents of total COPs in plasma of chicken consistently increased with the increase of OXL in the feeds in contrast to TFA feeds, although the levels of total cholesterol were rather similar. Dietary TFA is known to increase total plasma cholesterol and LDL-cholesterol and reduce HDL-cholesterol in humans [28]. It has been reported that TFA activates cholesteryl ester transfer protein (CETP) in rabbit and thereby increases plasma LDL-cholesterol level [6]. Our results from chickens fed TFA agree with that observation, so we can conclude that chickens also adopt the same mechanism as rabbits, with CETP activity increasing plasma LDL-cholesterol levels due to increased levels of TFA in the feeds.

It has been reported that thermally oxidized fats in feeds reduce $\alpha$-tocopherol in plasma and cause increased meat lipid oxidation [11]. In animals, the presence of COPs in the plasma depends on many factors e.g. rate of absorption from gut, transport to the specific tissues, elimination from the tissues by transport or metabolism, and the rate of their formation in vivo [24]. A diet high in oxidized lipids could increase endogenous oxidative stress, which may facilitate formation of COPs in vivo. One of the major factors influencing oxidative stress in plasma (in vivo) is antioxidant activity. The amount of dietary antioxidant is depleted in the oxidized lipid, resulting in 
increased in vivo lipid autoxidation and subsequently increased generation of COPs $[11,22,26,29]$.

A sunflower oil/olive oil blend (heated and fresh) was used for the OXL trials in this study. Sunflower oil is rich in 18:2n-6 and 18:3n-3, and olive oil is rich in 18:1n-9, and both oils contain high amounts of endogenous tocopherols. During heating of these oils, the amount of tocopherols in the oxidized lipid feed was reduced, resulting in final $\alpha$-tocopherol levels in low and high OXL feeds of 52 and $41 \mathrm{mg} / \mathrm{kg}$ feed, respectively (unpublished results). This caused lower tocopherol intake by the chicken and subsequent higher oxidation of cholesterol in plasma. The presence of a large number of oxidized compounds in thermally abused oils could also play an important role in degrading $\alpha$-tocopherol in plasma as well as in the gastrointestinal tract and thereby in increasing oxidation of cholesterol [30]. In our study, values of $\alpha$ tocopherol in plasma were 15.5 and $8.7 \mathrm{mg} / \mathrm{L}$ plasma, in animals from low and high OXL diets, respectively (unpublished results). The influence of the lower intake and lower deposit of tocopherol in tissues can be clearly seen comparing the values found for COPs in TFA trials and in OXL trials. In the chicken plasma, the content of 7-KC was lower than that of the other C7 oxycholesterols in the low and medium TFA and OXL feeding trials. This may be due to the rate of 7-KC breakdown, which was possibly higher than formation [31].

Moderate amounts of TFA and OXL in the feeds used in this study were shown to enhance the levels of cholesterol and COPs in the chicken tissues. This is a new study on the effects of feed fats containing TFA on the levels of cholesterol COPs in chicken. Although COPs in foods are considered potential health risk but there is no 
regulation limiting their levels in foods. The levels shown in this paper are far below than the literature value $(20 \mu \mathrm{g} / 100 \mathrm{~g}$ in fresh meat and $146 \mu \mathrm{g} / 100 \mathrm{~g}$ in cooked meat $)$ and can be considered as safe [10]. More studies are necessary using wider ranges of TFA and OXL in feeds for their long-term effects in chicken both in terms of animal welfare and on the oxidative stability of its edible tissues for high quality chicken for human consumption.

\section{Acknowledgments}

This work was financially supported by the EU Feeding Fats Safety Research Project (FOOD-CT2004-007020). E. Blas, Department of Animal Science, Polytechnic University of Valencia, Barcelona, and M. D. Baucells, Veterinary School, University Autonoma, Barcelona, Spain, for feed manufacturing, housing of animals and slaughtering and sampling facilities. Dietrich von Rosen, Swedish University of Agricultural Sciences, Uppsala, Sweden for statistical analysis. Instituto Danone for a research grant to A. Tres. 


\section{References}

1. Staprans I, Pan XM, Rapp JH, and Feingold KR (2003) Oxidized cholesterol in the diet is a source of oxidized lipoproteins in human serum. J Lipid Res 44:705-715

2. Moghadasian MH (2002) Experimental atherosclerosis: a historical overview. Life Sci 70:855-865

3. Hur SJ, Du M, Nam K, Williamson M, and Ahn DU (2005) Effect of dietary fats on blood cholesterol and lipid and the development of atherosclerosis in rabbits. Nutr Res 25:925-935

4. Schroepfer GJ (2000) Oxysterols: Modulators of cholesterol metabolism and other processes. Physiol Rev 80:361-554

5. Faulconnier Y, Roy A, Ferlay A, Chardigny JM, Durand D, Lorenz S, Gruffat D, and Chilliard Y (2006) Effect of dietary supply of butters rich either in trans-10-18: 1 or in trans-11-18: 1 plus cis-9, trans-11-18: 2 on rabbit adipose tissue and liver lipogenic activities. Brit J Nutr 96:461-468

6. Gatto LM, Lyons MA, Brown AJ, and Samman S (2001) Trans fatty acids and cholesterol metabolism: mechanistic studies in rats and rabbits fed semipurified diets. International Journal of Food Sciences and Nutrition 52:435-441

7. Javadi M, Geelen MJH, Everts H, Hovenier R, Javadi S, Kappert H, and Beynen AC (2008) Body composition and heat expenditure in broiler chickens fed diets with or without trans fatty acids. J Anim Physiol an N 92:99-104

8. Martinez VM, Newman RK, and Newman CW (1992) Barley Diets with Different Fat Sources Have Hypocholesterolemic Effects in Chicks. J Nutr 122:1070-1076

9. Skrivan M, Skrivanova V, Marounek M, Tumova E, and Wolf J (2000) Influence of dietary fat source and copper supplementation on broiler performance, fatty acid profile of meat and depot fat, and on cholesterol content in meat. Br Poult Sci 41:608-614

10. Kerry JP, Gilroy DA, and O'Brien NM (2002) Formation and Content of Cholesterol Oxidation Products in Meat and Meat Products. In: Guardiola F, Dutta PC, Codony R and Savage GP Cholesterol and Phytosterol Oxidation Products: Analysis, Occurrence, and Biological Effects. AOCS Press, Champaign, IL, pp. 162-185.

11. Grau A, Codony R, Grimpa S, Baucells MD, and Guardiola F (2001) Cholesterol oxidation in frozen dark chicken meat: influence of dietary fat source, and alpha-tocopherol and ascorbic acid supplementation. Meat Sci 57:197-208

12. Bonoli M, Caboni MF, Rodriguez-Estrada MT, and Lercker G (2007) Effect of feeding fat sources on the quality and composition of lipids of precooked ready-to-eat fried chicken parries. Food Chem 101:1327-1337 
13. Nuchi C, Guardiola F, Bou R, Bondioli P, Della Bella L, and Codony R (2009) Assessment of the Levels of Degradation in Fat Co-and Byproducts for Feed Uses and Their Relationships with Some Lipid Composition Parameters. J Agr Food Chem 57:1952-1959

14. National Research Council N (1994) Nutrient Requirements of Poultry, National Academy Press, Washington, DC

15. Rule DC, Broughton KS, Shellito SM, and Maiorano G (2002) Comparison of muscle fatty acid profiles and cholesterol concentrations of bison, beef cattle, elk, and chicken. J Anim Sci 80:1202-1211

16. Larkeson B, Dutta PC, and Hansson I (2000) Effects of frying and storage on cholesterol oxidation in minced meat products. J Am Oil Chem Soc 77:675-680

17. Hara A, and Radin NS (1978) Lipid Extraction of Tissues with a Low-Toxicity Solvent. Anal Biochem 90:420-426

18. Ubhayasekera SJKA, Verleyen T, and Dutta PC (2004) Evaluation of GC and GCMS methods for the analysis of cholesterol oxidation products. Food Chem 84:149-157

19. Appelqvist L-Å, Dutta PC, Lidbeck A, and Jameson S, Reduction of polyunsaturated fatty acid- and cholesterol-oxidation in diabetics supplemented with antioxidants, in Oxygen-95. The Annual Meeting of The Oxygen Society, The Oxygen Society, San Francisco, CA, Pasadena,California, 1995, p. 53.

20. Simsek UG, Dalkilic B, Ciftci M, Cerci IH, and Bahsi M (2009) Effects of Enriched Housing Design on Broiler Performance, Welfare, Chicken Meat Composition and Serum Cholesterol. Acta Vet Brno 78:67-74

21. Maraschiello C, Sarraga C, Esteve-Garcia E, and Regueiro JAG (2000) Dietary iron and copper removal does not improve cholesterol and lipid oxidative stability of raw and cooked broiler meat. J Food Sci 65:211-214

22. Maraschiello C, Esteve E, and Regueiro JAG (1998) Cholesterol oxidation in meat from chickens fed alpha-tocopherol- and beta-carotene-supplemented diets with different unsaturation grades. Lipids 33:705-713

23. Kuhnt K, Wagner A, Kraft J, Basu S, and Jahreis G (2006) Dietary supplementation with 11 trans- and 12trans-18:1 and oxidative stress in humans. American Journal of Clinical Nutrition 84:981-988

24. Diczfalusy U (2002) Origin and Content of Cholesterol Oxidation Products in Biological Samples. In: Guardiola F, Dutta PC, Codony R and Savage GP Cholesterol and Phytosterol Oxidation Products: Analysis, Occurrence, and Biological Effects. AOCS Press, Champaign, IL, pp. 217-240

25. Bjorkhem I, and Diczfalusy U (2002) Oxysterols - Friends, foes, or just fellow passengers? Arterioscl Throm Vas 22:734-742 
26. Bou R, Codony R, Baucells MD, and Guardiola F (2005) Effect of heated sunflower oil and dietary supplements on the composition, oxidative stability, and sensory quality of dark chicken meat. J Agr Food Chem 53:7792-7801

27. Galvin K, Morrissey PA, and Buckley DJ (1998) Cholesterol oxides in processed chicken muscle as influenced by dietary alpha-tocopherol supplementation. Meat Sci 48:1-9

28. Combe N, Clouet P, Chardigny JM, Lagarde M, and Leger CL (2007) Trans fatty acids, conjugated linoleic acids, and cardiovascular diseases. Eur J Lipid Sci Tech 109:945953

29. Monahan FJ, Gray JI, Booren AM, Miller ER, Buckley DJ, Morrissey PA, and Gomaa EA (1992) Influence of Dietary-Treatment on Lipid and Cholesterol Oxidation in Pork. J Agr Food Chem 40:1310-1315

30. Sheehy PJA, Morrissey PA, and Flynn A (1993) Influence of Heated Vegetable-Oils and Alpha-Tocopheryl Acetate Supplementation on Alpha-Tocopherol, Fatty-Acids and Lipid-Peroxidation in Chicken Muscle. Brit Poultry Sci 34:367-381

31. Osada K (2002) Cholesterol Oxidation Products: Other Biological Effects. In: Guardiola F, Dutta PC, Codony R and Savage GP Cholesterol and Phytosterol Oxidation Products: Analysis, Occurrence, and Biological Effects. AOCS Press, Champaign, IL, pp. 278-318 


\section{Figure captions}

Figure 1: GC-MS chromatogram showing resolution of standard samples of some common cholesterol oxidation products. GC-MS conditions are described in

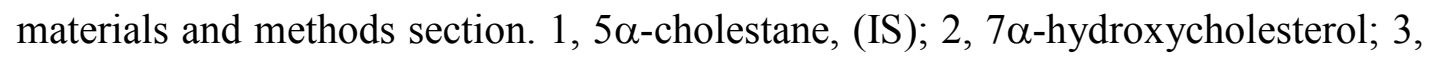
7 $\beta$-hydroxycholesterol; 4, 20 $\alpha$-hydroxycholesterol; 5, Cholesterol-5 $\beta, 6 \beta$-epoxide; 6, Cholesterol-5 $\alpha, 6 \alpha$-epoxide; 7, cholestanetriol; 8, 25-hydroxycholesterol; 9, 7ketocholesterol.

Figure 2: Full scan MS spectra of 5 $\alpha$-cholestane (IS) and trimethylsilyl ether (TMS) derivatives of standard sample of oxycholesterols from the corresponding peaks 1-9,

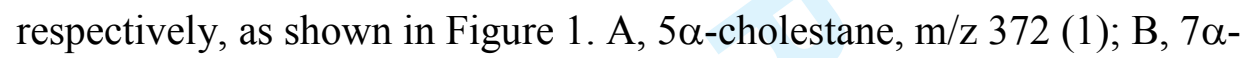
hydroxycholesterol, m/z 546 (2); C, 7 $\beta$-hydroxycholesterol, m/z 546 (3); D, $20 \alpha-$ hydroxycholesterol, m/z 546, 461, 201 (4); E, Cholesterol-5 $\beta, 6 \beta$-epoxide, m/z 474 (5); F, Cholesterol-5 $\alpha, 6 \alpha$-epoxide, m/z 474 (6); G, cholestanetriol, m/z 564 (7); H, 25hydroxycholesterol, m/z 546, 131 (8); I, 7-ketocholesterol, m/z 472 (9).

Figure 3: a, Contents of cholesterol in chicken meat at three levels of trans fatty acid (TFA) and oxidized lipid (OXL) in feed; b, Contents of cholesterol in chicken liver at three levels of TFA and OXL in feed; c, Contents of cholesterol in chicken plasma at three levels of TFA and OXL in feed. L, low level; M, medium level; H, high level. 


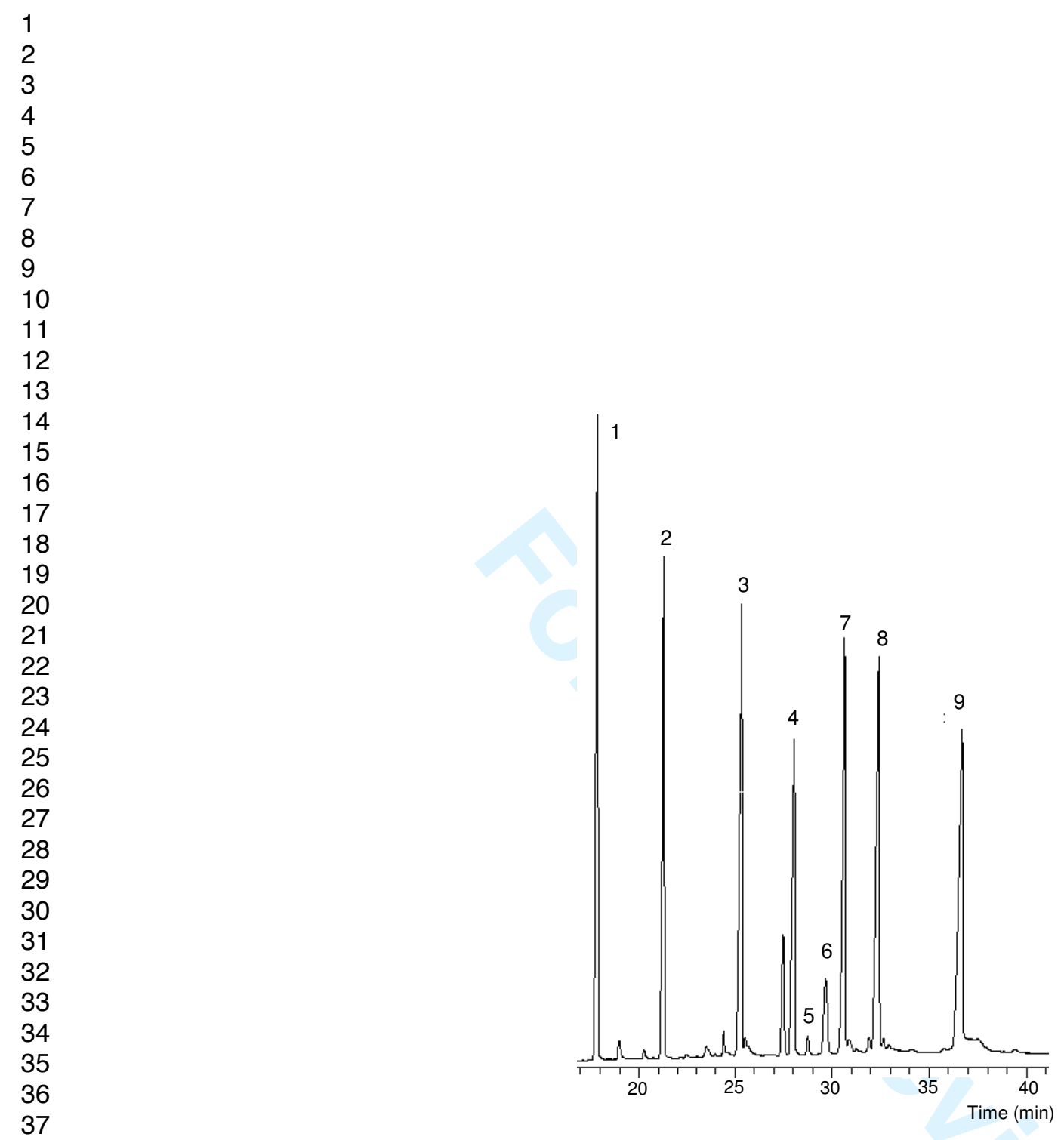

Figure 1

42

43

44

45

46

47

48

49

50

51

52

53

54

55

56

57

58

59

60 

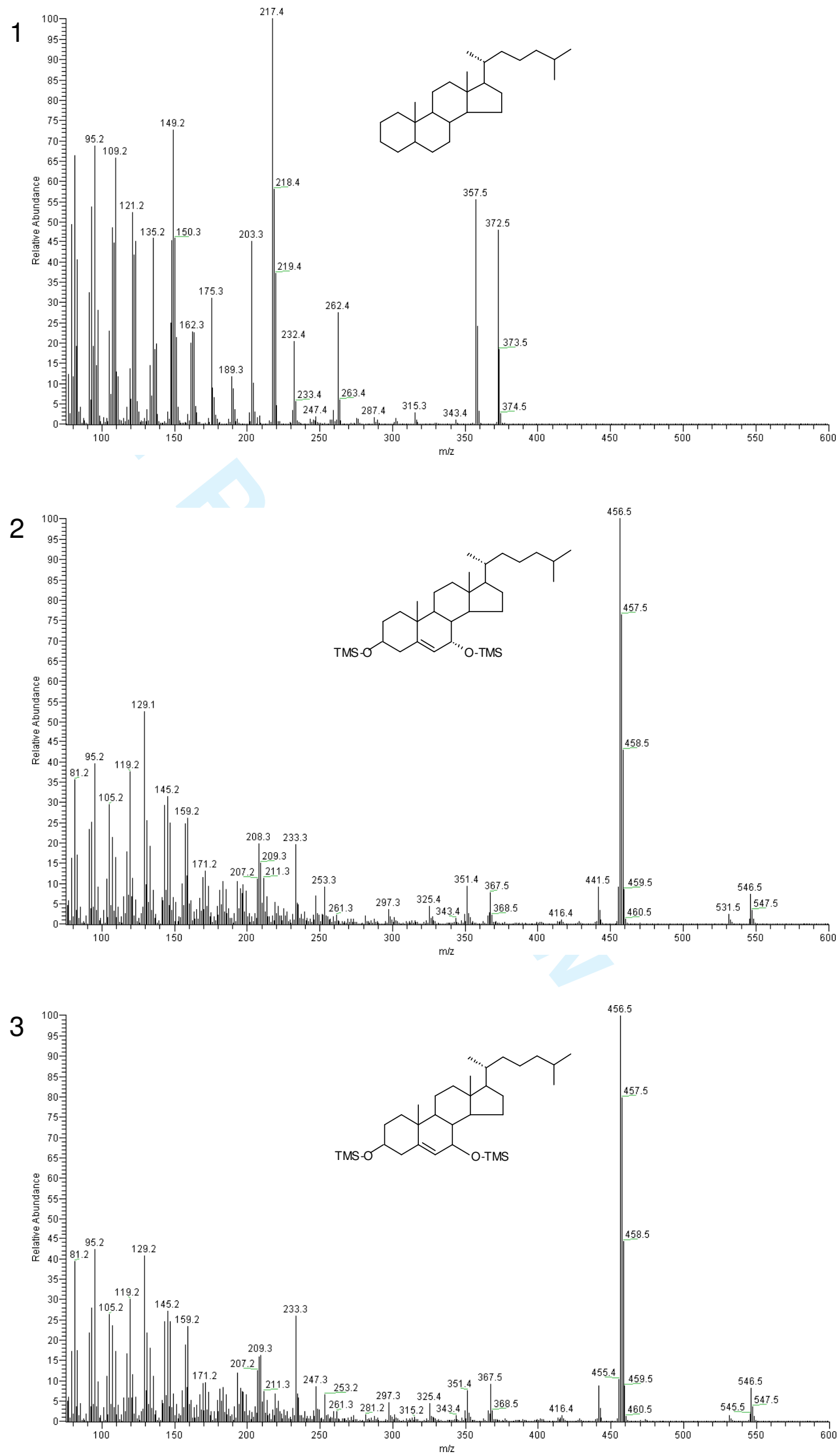
4

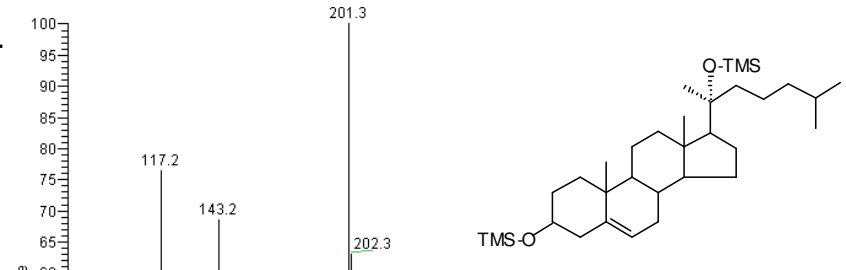

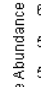

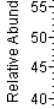

45
40 年
35 F $^{5}$

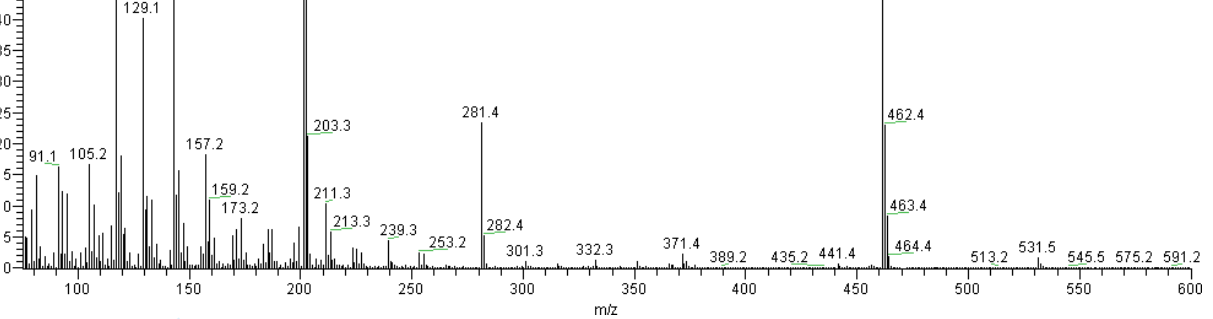

5

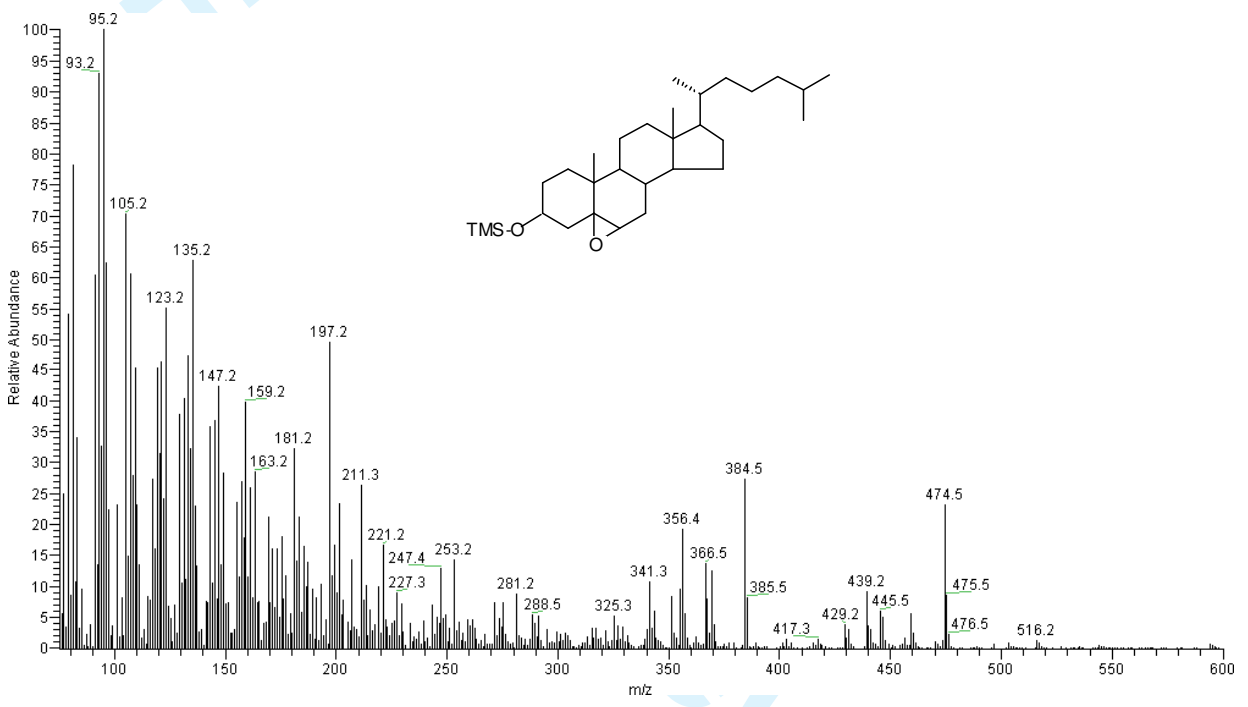

6

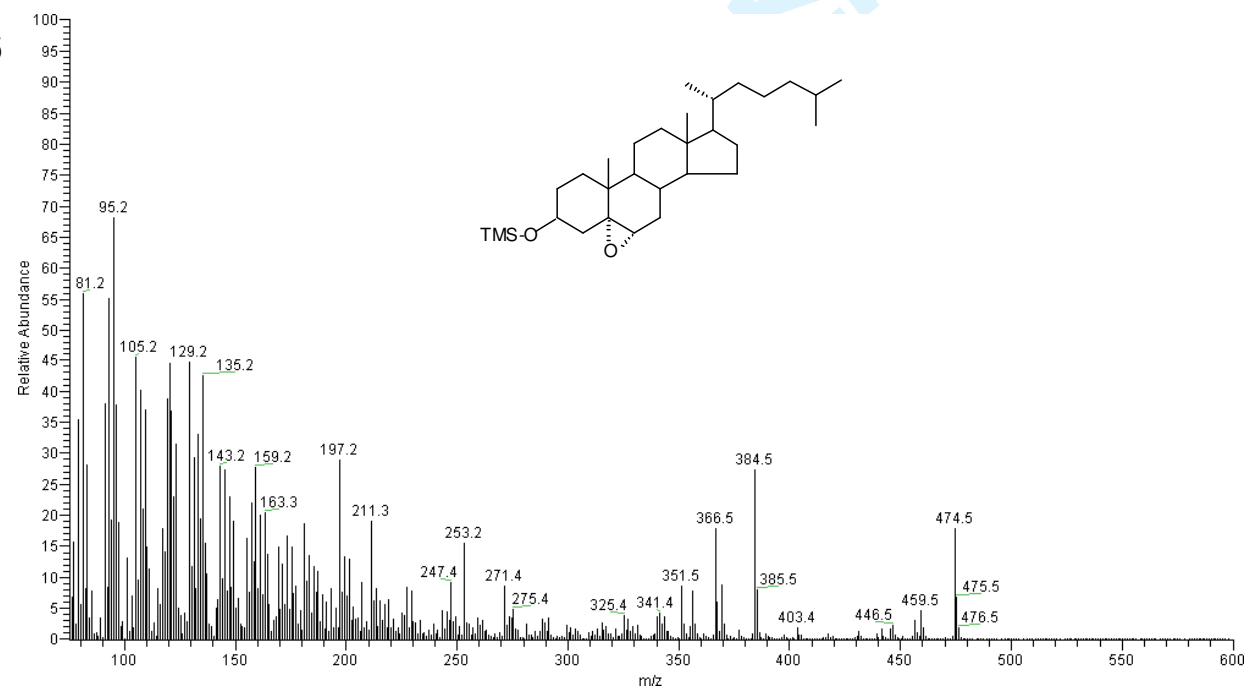



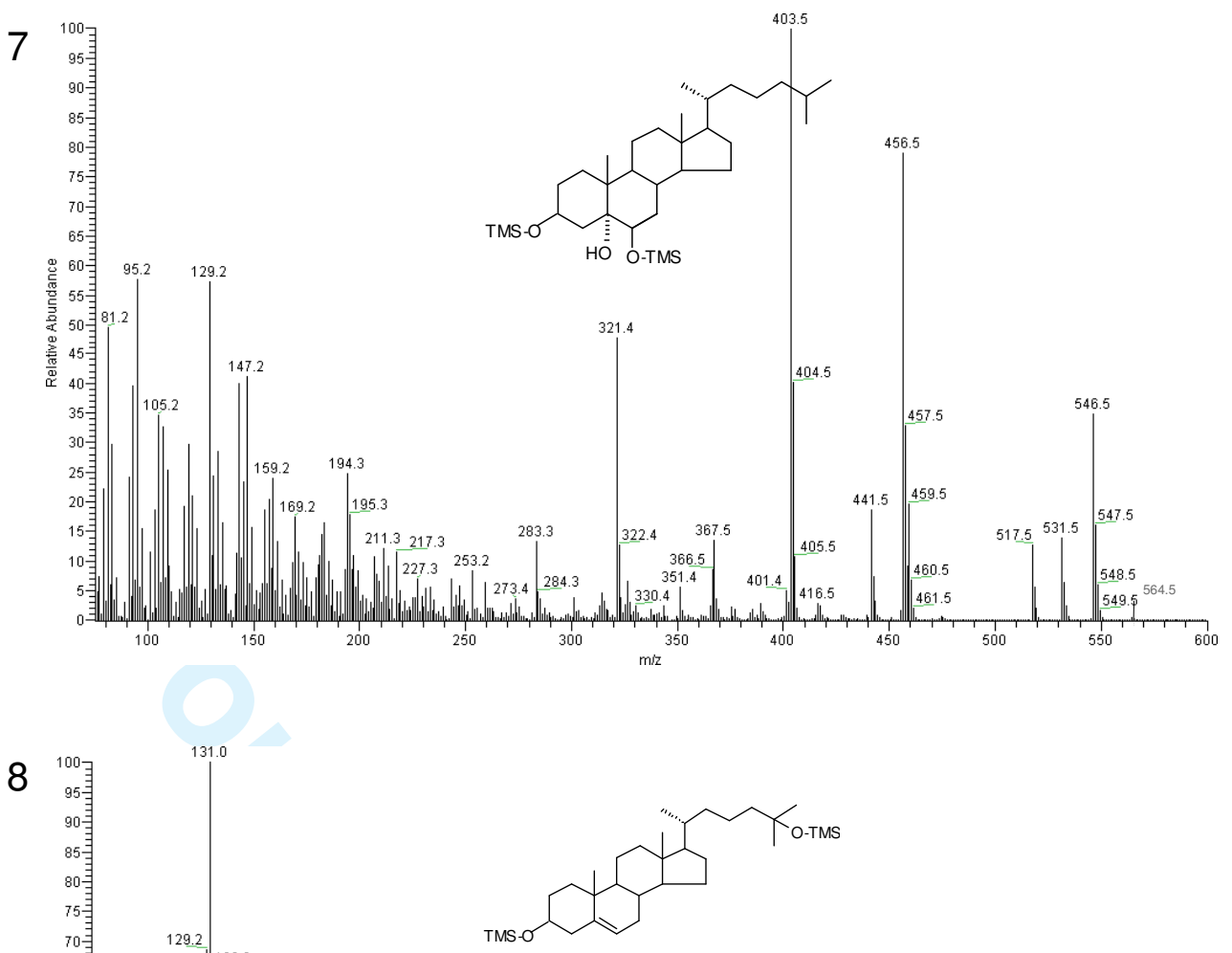

Figure 2

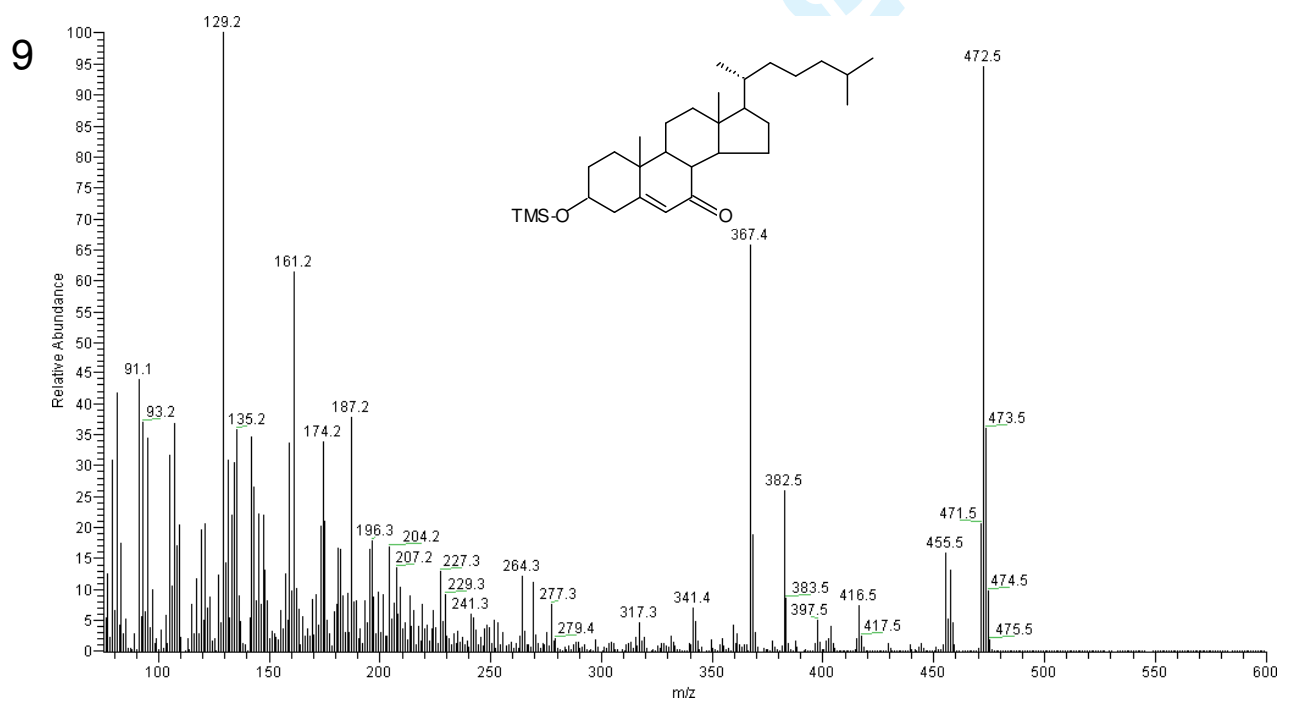


a

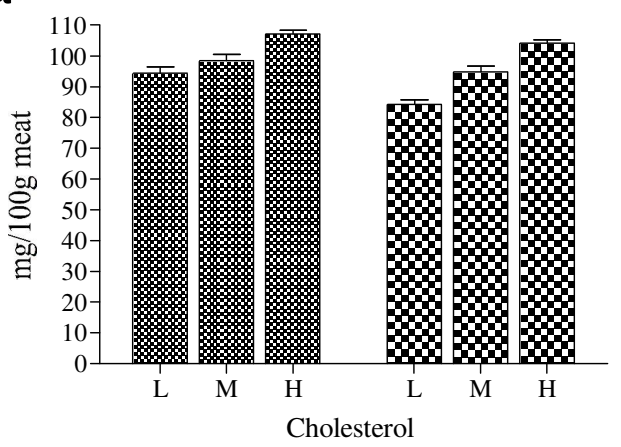

b
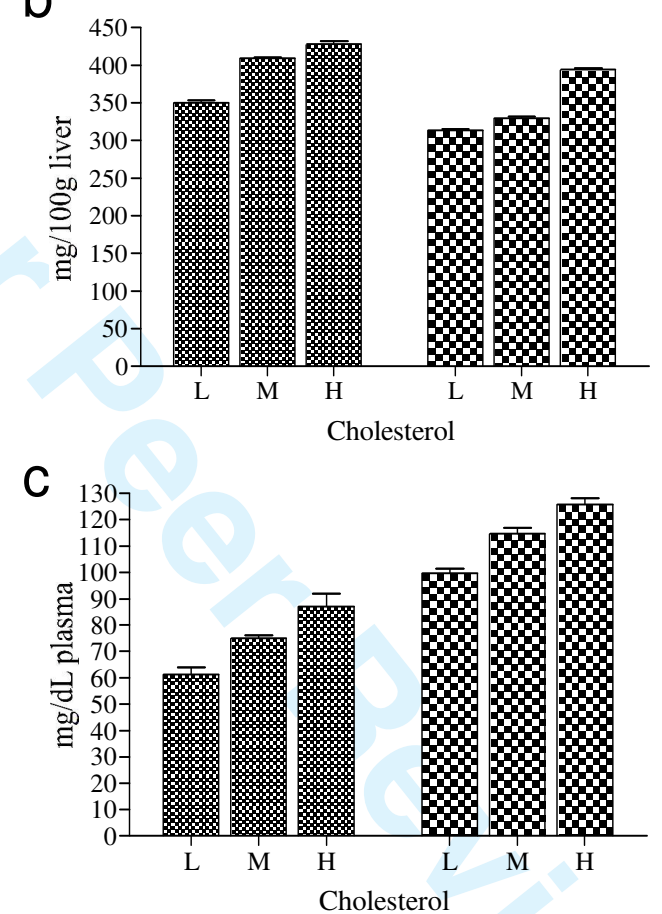

\&\& TFA

EA OXL

Figure 3 
Table 1: Ingredients and nutrient composition of the basal chicken feed

\begin{tabular}{lrll}
\hline \multicolumn{1}{c}{ Ingredient (\%) } & \multicolumn{2}{c}{ Nutrient composition (\%) } \\
\hline Corn & 52.7 & Metabolizable energy (kcal/kg) & 4,968 \\
Soybean meal (47\% of CP) & 30.0 & Dry matter & 90.8 \\
Added fat material & 6.0 & Crude protein & 21.1 \\
Full fat soyabean & 6.0 & Ether extract & 9.5 \\
HCl L-Lysine & 0.3 & Crude fiber & 3.8 \\
DL-methionine (99\%) & 0.2 & Ash & 6.5 \\
Dicalcium phosphate & 2.5 & & \\
Calcium carbonate & 1.3 & & \\
Salt & 0.5 & & \\
Vitamin and mineral premix & 0.5 & & \\
${ }^{*}$ Composition of vitamin and mineral premix (1kg of feed contained): Vitamin A: 6000
\end{tabular}

*Composition of vitamin and mineral premix (1 kg of feed contained): Vitamin A: 6000 $\mathrm{UI}$; vitamin $\mathrm{D}_{3}$ : $1200 \mathrm{UI}$; vitamin $\mathrm{E}: 10 \mathrm{mg}$; vitamin $\mathrm{K}_{3}: 1.5 \mathrm{mg}$; vitamin $\mathrm{B}_{1}: 1.1 \mathrm{mg}$; vitamin $\mathrm{B}_{2}: 4 \mathrm{mg}$; vitamin $\mathrm{B}_{6}: 1.5 \mathrm{mg}$; vitamin $\mathrm{B}_{12}: 9 \mu \mathrm{g}$; folic acid: $4 \mathrm{mg}$; biotin: $50 \mu \mathrm{g}$; pantothenic acid $6 \mathrm{mg}$ : nicotinic acid: $21 \mathrm{mg}$; choline: $360 \mathrm{mg}$; Mn: $75 \mathrm{mg}$; Zn: $50 \mathrm{mg}$; I: $0.18 \mathrm{mg}$; Fe: $30 \mathrm{mg}$; Cu: $6 \mathrm{mg}$; Se: 0.2; Co: 0.2; ethoxiquin: $16 \mathrm{mg}$; addition of choline chloride $15 \mathrm{mg}$. 
Table 2: Retention times (RT) and relative retention times (RRT) of oxycholesterols (COPs) separated on two dimensional capillary GC ${ }^{\mathrm{a}}$

\begin{tabular}{|c|c|c|c|}
\hline COPs & $\begin{array}{c}\text { Peak } \\
\text { number }\end{array}$ & $\mathrm{RT}$ (min) & RRT \\
\hline $5 \alpha$-cholestane (IS) & 1 & 17.88 & \\
\hline $7 \alpha$-hydroxycholesterol & 2 & 21.29 & 1.19 \\
\hline 7 $\beta$-hydroxycholesterol & 3 & 25.36 & 1.42 \\
\hline 7-ketocholesterol & 9 & 36.70 & 2.05 \\
\hline 20a-hydroxycholesterol & 4 & 28.06 & 1.57 \\
\hline Cholesterol-5 $\alpha, 6 \alpha$-epoxide & 5 & 29.67 & 1.66 \\
\hline Cholesterol- $5 \beta, 6 \beta$-epoxide & 6 & 28.76 & 1.61 \\
\hline Cholestanetriol & 7 & 30.41 & 1.70 \\
\hline 25- hydroxycholesterol & 8 & 32.41 & 1.81 \\
\hline
\end{tabular}


Table 3: Content of cholesterol oxidation products (COPs) in chicken meat at three different levels of trans fatty acid (TFA) and oxidized lipid (OXL) feeds (mean of 4 replicates per treatment)

\begin{tabular}{|c|c|c|c|c|c|c|}
\hline \multicolumn{7}{|c|}{ Chicken meat $(\mu \mathrm{g} / 100 \mathrm{~g} \pm \mathrm{SD})$} \\
\hline \multirow{2}{*}{ COPs } & \multicolumn{3}{|c|}{ TFA } & \multicolumn{3}{|c|}{ OXL } \\
\hline & Low & Medium & High & Low & Medium & High \\
\hline $7 \alpha-\mathrm{HC}$ & $6.47( \pm 0.65)$ & $8.13( \pm 0.53)$ & $12.08( \pm 1,04)$ & $2.94( \pm 0.37)$ & $2.82( \pm 0.21)$ & $5.88( \pm 0.75)$ \\
\hline $7 \beta-\mathrm{HC}$ & $6.01( \pm 0.52)$ & $8.56( \pm 0.37)$ & $11.32( \pm 0.68)$ & $2.48( \pm 0.37)$ & $5.57( \pm 1.11)$ & $4.22( \pm 1.82)$ \\
\hline 7-KC & $3.03( \pm 1.45)$ & $7.48( \pm 0.47)$ & $20.77( \pm 2.63)$ & $7.46( \pm 0.13)$ & $13.44( \pm 0.9)$ & $29.13( \pm 1.24)$ \\
\hline$\alpha-\mathrm{CE}$ & nd & $\operatorname{tr}$ & $1.14( \pm 0.17)$ & nd & $\operatorname{tr}$ & $6.37( \pm 1.36)$ \\
\hline$\beta-\mathrm{CE}$ & $1.94( \pm 0.64)$ & $\operatorname{tr}$ & $2.70( \pm 1.7)$ & nd & $1.07( \pm 0.09)$ & $2.92( \pm 1.11)$ \\
\hline $\mathrm{CT}$ & nd & nd & nd & nd & nd & $5.13( \pm 0.63)$ \\
\hline 25-HC & nd & nd & nd & nd & $\operatorname{tr}$ & $21.59( \pm 1.75)$ \\
\hline Total & $17.45^{a}$ & $24.17^{a}$ & 48.01 ${ }^{a}$ & $\mathbf{1 2 . 8 8}^{b}$ & $22.90^{b}$ & $\mathbf{7 5 . 2 4 ^ { b }}$ \\
\hline
\end{tabular}

tr, below the quantification; (>0.1 $\mu \mathrm{g} / 100 \mathrm{~g})$; nd, not detected; $7 \alpha$-HC, $7 \alpha$-hydroxycholesterol; $7 \beta-\mathrm{HC}$, 7 $\beta$-hydroxycholesterol;

$\beta$-CE, $\beta$-epoxycholesterol; $\alpha$-CE, $\alpha$-epoxycholesterol; CT, cholesteroltriol; $25-\mathrm{HC}, 25$-hydroxycholesterol; 7-KC,

7-ketocholesterol; ${ }^{a}$ significant increment of total and individual COPs at $0.01<p \leq 0.05$ in chicken meat from low to high

TFA feeding trials; ${ }^{b}$ significant increment of total and individual COPs at $0.01<p \leq 0.05$ in chicken meat from low to high OXL

feeding trials 
Table 4: Content of cholesterol oxidation products (COPs) in chicken liver at three different levels of trans fatty acid (TFA) and oxidized lipid (OXL) feeds (mean of 4 replicates per treatment)

\begin{tabular}{llllccc}
\hline \multicolumn{7}{c}{ Chicken liver $(\mu \mathrm{g} / 100 \mathrm{~g} \pm \mathrm{SD})$} \\
\hline \multirow{2}{*}{ COPs } & \multicolumn{7}{c}{ LFA } & Medium & High & Low & $\begin{array}{c}\text { OXL } \\
\text { Medium }\end{array}$ & High \\
\hline $7 \alpha-\mathrm{HC}$ & $4.50( \pm 0.24)$ & $4.52( \pm 0.83)$ & $6.18( \pm 0.63)$ & $5.25( \pm 0.03)$ & $12.36( \pm 0.33)$ & $15.68( \pm 1.98)$ \\
$7 \beta-\mathrm{HC}$ & $5.06( \pm 0.48)$ & $7.47( \pm 1.48)$ & $5.26( \pm 1.18)$ & $5.08( \pm 0.77)$ & $7.53( \pm 1.49)$ & $11.95( \pm 0.95)$ \\
$7-$ KC & $3.96( \pm 0.52)$ & $4.47( \pm 1,18)$ & $6.36( \pm 0.61)$ & $4.67( \pm 0.56)$ & $9.13( \pm 1.26)$ & $11.87( \pm 0.5)$ \\
$\alpha-\mathrm{CE}$ & $2.19( \pm 0.14)$ & $3.76( \pm 0.93)$ & $6.77( \pm 0.57)$ & $5.20( \pm 1.25)$ & $6.80( \pm 1.27)$ & $6.12( \pm 0.86)$ \\
$\beta-\mathrm{CE}$ & $2.93( \pm 0.15)$ & $7.94( \pm 1.43)$ & $9.27( \pm 1.25)$ & $5.24( \pm 0.95)$ & $5.75( \pm 0.71)$ & $5.88( \pm 1.17)$ \\
CT & nd & nd & $4.54( \pm 1.49)$ & $2.75( \pm 0.51)$ & $4.14( \pm 0.93)$ & $3.60( \pm 1.14)$ \\
$25-\mathrm{HC}$ & nd & nd & $4.00( \pm 0.72)$ & $2.14( \pm 0.51)$ & $3.65( \pm 1.56)$ & $3.26( \pm 0.58)$ \\
Total & $\mathbf{1 8 . 6 4}^{a}$ & $\mathbf{2 8 . 1 6}^{a}$ & $\mathbf{4 2 . 3 8}^{a}$ & $\mathbf{3 0 . 3 3}^{b}$ & $\mathbf{4 9 . 3 6}^{b}$ & $\mathbf{5 8 . 3 6}^{b}$ \\
\hline
\end{tabular}

tr, below the quantification; $(>0.1 \mu \mathrm{g} / 100 \mathrm{~g})$; nd, not detected; $7 \alpha-\mathrm{HC}, 7 \alpha$-hydroxycholesterol; $7 \beta-\mathrm{HC}$,

$7 \beta$-hydroxycholesterol; $\beta$-CE, $\beta$-epoxycholesterol; $\alpha$-CE, $\alpha$-epoxycholesterol; CT, cholesteroltriol; 25 -HC,

25-hydroxycholesterol; 7-KC, 7-ketocholesterol; ${ }^{a}$ significant increment of total and individual COPs at $0.01<p \leq 0.05$ in chicken liver from low to high TFA feeding trials; ${ }^{b}$ significant increment of total COPs at $0.01<p \leq 0.05$ in chicken liver from low to high OXL feeding trials. 
Table 5: Content of cholesterol oxidation products (COPs) in chicken plasma at three different levels of trans fatty acid (TFA) and oxidized lipid (OXL) feeds (mean of 4 replicates per treatment)

\begin{tabular}{lllllll}
\hline \multicolumn{7}{c}{ Chicken plasma $(\mu \mathrm{g} / \mathrm{dL} \pm \mathrm{SD})$} \\
\hline \multirow{2}{*}{ COPs } & \multicolumn{1}{c}{ Low } & \multicolumn{1}{c}{ TFA } & \multicolumn{1}{c}{ Medium } & \multicolumn{1}{c}{ High } & \multicolumn{1}{c}{ Low } & \multicolumn{1}{c}{ OXL } \\
& \multicolumn{1}{c}{ Medium } & \multicolumn{1}{c}{ High } \\
\hline $7 \alpha$-HC & $15.32( \pm 2.67)$ & $14.39( \pm 2.59)$ & $14.63( \pm 1.52)$ & $6.20( \pm 1.81)$ & $16.89( \pm 1.36)$ & $33.48( \pm 0.94)$ \\
$7 \beta-H C$ & $13.77( \pm 0.42)$ & $36.05( \pm 1.73)$ & $24.49( \pm 2.43)$ & $11.69( \pm 1.17)$ & $29.50( \pm 3.56)$ & $34.68( \pm 2.8)$ \\
$7-$ KC & $3.18( \pm 1.86)$ & $2.55( \pm 0.61)$ & $15.39( \pm 0.18)$ & $5.31( \pm 0.69)$ & $6.20( \pm 1.33)$ & $33.59( \pm 2.09)$ \\
$\alpha-C E$ & $7.53( \pm 1.40)$ & $5.66( \pm 1.53)$ & $11.84( \pm 2.34)$ & $12.70( \pm 1.27)$ & $15.02( \pm 3.59)$ & $33.08( \pm 8.18)$ \\
$\beta-C E$ & $56.87( \pm 3.72)$ & $47.52( \pm 1.36)$ & $54.31( \pm 3.08)$ & $24.37( \pm 1.94)$ & $37.47( \pm 6.47)$ & $46.05( \pm 8.42)$ \\
CT & $1.15( \pm 0.15)$ & $1.16( \pm 0.14)$ & $1.36( \pm 0.25)$ & $2.50( \pm 0.66)$ & $1.67( \pm 0.41)$ & $9.47( \pm 2.57)$ \\
$25-H C$ & $6.80( \pm 3.77)$ & $2.07( \pm 1.74)$ & $4.27( \pm 1.86)$ & $2.82( \pm 0.84)$ & $4.25( \pm 1.43)$ & $18.16( \pm 7.12)$ \\
Total & $\mathbf{1 0 4 . 6 2}^{a}$ & $\mathbf{1 0 9 . 4 0}^{a}$ & $\mathbf{1 2 6 . 2 9}^{a}$ & $\mathbf{6 5 . 5 9}^{b}$ & $\mathbf{1 1 1 . 0 0}^{b}$ & $\mathbf{2 0 8 . 5 1}^{b}$ \\
\hline
\end{tabular}

tr, below the quantification; $(>0.1 \mu \mathrm{g} / 100 \mathrm{~g})$; nd, not detected; $7 \alpha$-HC, $7 \alpha$-hydroxycholesterol; $7 \beta$-HC,

7 $\beta$-hydroxycholesterol; $\beta$-CE, $\beta$-epoxycholesterol; $\alpha$-CE, $\alpha$-epoxycholesterol, CT, cholesteroltriol; $25-\mathrm{HC}, 25$ -

hydroxycholesterol; 7-KC, 7-ketocholesterol; ${ }^{a}$ significant increment of total and individual COPs at $0.01<p \leq 0.05$

in chicken plasma from low to high TFA feeding trials; ${ }^{b}$ significant increment of total and individual COPs at $0.01<p \leq 0.05$

in chicken plasma from low to high OXL feeding trials. 